\title{
連続式顆粒化装置における粉砕原料粒子径が顆粒物性に与える影響
}

\author{
松井 航*，富田 陽介，土井 尚俊，長門 环也
}

\section{Effect of API Particle Size Applied to Continuous Granulator against Characteristics of Prepared Granules}

\author{
Kou Matsui*, Yosuke Tomita, Naotoshi Doi and Takuya Nagato
}

Received 10 January 2020; Accepted 17 March 2020

\begin{abstract}
Particle size of raw materials is one of the most important factors in granulation, a general particle processing method. Especially in the case of granulation of multiple materials, component uniformity depends on the particle size. Therefore, pulverizing raw materials to a smaller particle size before granulation is often selected as a preprocessing method. Currently, there is a direct granule producing apparatus, which produces granules direct from a suspension of raw materials. The granules produced from this apparatus have unique features such as content uniformity, spherical shape, and high content yield due to less addition of excipients. From these features, the granules have advantages-such as ease to swallow and downsizing of final dosage form if they used for drugs. Here, we describe the necessity of raw material pulverization by confirming the correlation between particle size of the pulverized raw material and component uniformity of the granules produced by direct granule producing apparatus.
\end{abstract}

Keywords: Particle direct granule producing apparatus, Component uniformity, Spherical shape, High content yield, Raw material pulverization.

\section{1. 緒言}

医薬品業界における一般的な錠剤製造プロセスは，粉 砕, 混合, 造粒, 乾燥, 整粒, 滑沢剂混合, 打錠, 錠剤 コーティングで行われる。その中で，造粒前の原料を粉 砕することが一般的である。この粉砕工程は, 薬物含量 の均一化, 薬物の溶解性向上を目的に実施される。特に 近年医薬品分野については活性が高い薬物が多く, 薬物 量は微量となり微量薬物含量の均一化が課題となってい る。そのため適切な粉砕条件を見出し, 薬物含量を均一 化することが重要である。また，粉砕で得られた原料は 粒子径が小さいため，流動性が悪くなる傾向があり，流 動層造粒などでは粒子が流動しにくく造粒が困難となる ケースもあり，流動化剤と呼ばれる流動を促進する賦形 剂を添加して造粒を行うことがある。

造粒の目的は, 薬物含量均一性, 流動性の向上などが 挙げられる。流動性については粒子径を大きくすること と, 理想的には粒子形状が球であることが望まれる。

近年の流動層技術による粒子加工方法として懸濁液を スプレーし，その固形分を粉末化した粒子を流動層内部

\footnotetext{
株式会社パウレック

（† 664-0837 兵庫県伊丹市北河原 5-5-5）

POWREX CORPORATION

(5-5-5 Kita-Gawara, Itami, Hyogo 664-0837, Japan)

* Corresponding Author k-matsui@powrex.co.jp
}

で造粒させ, 必要な粒子径分布を有する粒子のみを回収 する技術がある。スプレー液には造粒を進行させるため に結合剤や賦形剂を溶解もしくは分散させ, スプレーし た多成分を含むミストから顆粒を徐々に成長させるため, 比較的球形かつ回収時の分級作用によって粒子径分布が 整った顆粒を得ることができる。本製法についても前処 理である粉砕プロセスは必要不可欠であり, 顆粒の薬物 含量の均一性, 球形な形状の顆粒を得るには薬物の微細 化が要求される。なお微細化の程度については現在検討 された事例がない。

そこで本研究では上述した新たな粒子機能加工である 連続式直接顆粒化技術を用い, 粉砕粒子径と得られた機 能性顆粒の球形度および有効成分である薬物含量の均一 性の関係について研究を行った。

\section{2. 実験装置}

本研究で用いた顆粒化装置および粉砕装置を示す。

\section{1 顆粒化装置}

顆粒化には連続式顆粒化装置（CTS-SGR-01（株）パウ レック）を用いた。Fig. 1 に構造図を示す。

本装置は顆粒化, 吸引, 分級, 連続的回収の機能を有 している。流動層底部に備え付けられたスプレーノズル から固形物を含む溶液もしくは懸濁液を噴霧することで, 乾燥によりシード粒子（核）を生成し, さらにシード粒 子の表面をレイヤリングすることにより，顆粒を製する。 


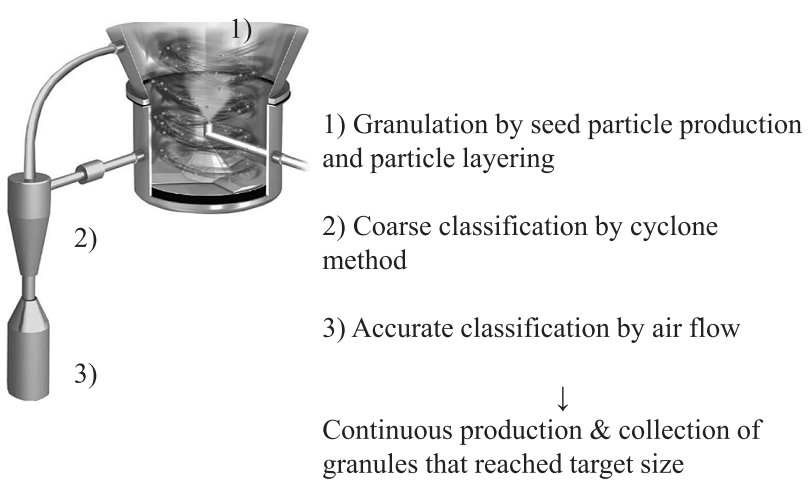

Fig. 1 Diagram of ConTinuouS-Spray Granulator

得られた顆粒はサイクロン方式による粗分級を行った 後, 流動層方式の風力分級装置により, 精密な分級操作 を行うことで所望粒子径の顆粒のみを回収できる。所望 粒子径に満たない微小粒子は, 流動層内に戻り, 引き続 きレイヤリングによって顆粒成長が行われる機構となっ ている。

\section{2 粉砕装置}

粉砕には高圧ホモジナイザ方式を採用した。用いた高 圧ホモジナイザの構造を Fig. 2 に示す。

本装置は高圧による乳化・分散装置であり, ナノエマ ルションの調製や凝集物の解砕, 粉砕, カプセル化など の処理を行うことができる。原理は一次側の圧縮された 油圧をもとにプランジャーを介して圧力を増幅させ， イ ンターアクションチャンバー（IXC）内の微小経路を通 過する際に最高 $207 \mathrm{MPa}$ の高圧力を原料に与え, 粉砕す ることができる。なお，粉砕回数 (パス回数)を繰り返 すことで所望の粒子径まで微粒化することが可能である。

\section{3. 実験方法}

本研究の実験フローを Fig. 3 に示す。

前処理として, Fig. 3 に示す条件によって原料の微粒 化を行った。微粒化を実現するために粉砕パラメータの ひとつである粉砕回数を変更し, サンプルを得た。得ら れた粉砕原料については，レーザー回析・散乱式粒子径 分布測定装置（マイクロトラックベル（株）MT3000）に て平均粒子径を測定した。また光学顕微鏡（OLYMPUS

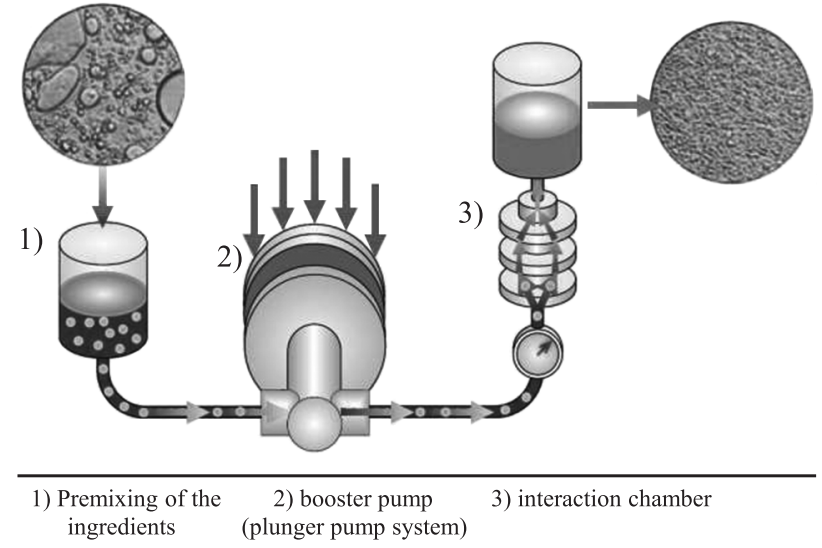

Fig. 2 Diagram of high-pressure homogenizer

（株）BX41）による観察も合わせて実施した。

次に Table 1～3 に示す 3 種の処方（Table 1～2 は湿式 粉砕処理を実施）の懸濁液を連続式顆粒化装置にて， ス プレー噴霧し，懸濁液中固形分の顆粒化を行った。層内 に一定の顆粒が得られた状態においてサンプリングを行 い, 得られた顆粒を走查電子顕微鏡（日本電子（株） JSM-6010PLUS）にて SEM 写真を撮影し, 得られた写真 から円形度を算出した。

円形度の算出

円形度 $\psi \mathrm{c}=(4 \times$ 円周率 $\times$ 面積 $) /(\text { 周囲長 })^{2}$

円形度は真円形状のときに最大值 1 をとり, 細長い形 状になると 0 に近づく。

円形度の值はばらつきが生じやすいので，本検討では 10 個の顆粒を測定しその平均値にて比較した。

また得られた顆粒を穊にて粒度別に分級し, 粒度別の 薬物含量を高速液体クロマトグラフィ（日本ウォーター ズ（株）ACQUITY Arc）にて測定した。

\section{4. 結果と考察}

処方中の懸濁物質の粒子径が連続式顆粒化装置で得ら れる顆粒の球形度などの諸物性におよぼす影響について 検討した。

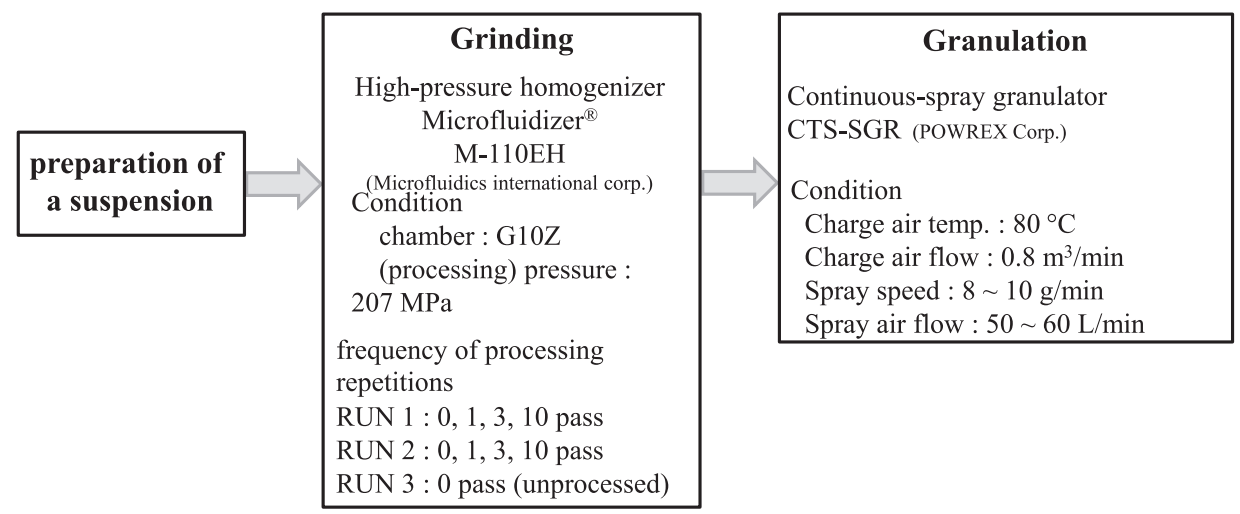

Fig. 3 Flow chart of experimental procedure 
Table 1 Materials for experiment

\begin{tabular}{llcc}
\hline Materials & Manufacturer & $\begin{array}{c}\text { Mixing ratio } \\
\text { of the water } \\
\text { solution (wt.\%) }\end{array}$ & $\begin{array}{c}\text { Mixing ratio } \\
\text { of granules (wt. } \%)\end{array}$ \\
\hline Ethenzamide & IWAKI SEIYAKU CO., LTD. & $2.8 \%$ & $14.0 \%$ \\
Lactose & DFE Pharma & $11.2 \%$ & $56.0 \%$ \\
Corn starch & Matsutani Chemical Industry Co., Ltd. & $4.8 \%$ & $24.0 \%$ \\
Hydroxypropyl Cellulose & NIPPON SODA CO., LTD. & $1.2 \%$ & $6.0 \%$ \\
\hline
\end{tabular}

\section{1 粉砕処理が顆粒の球形化と粒度別含量におよぼす 影響}

本実験に用いた処方を Table 1 に示す。

本研究では解熱鎮痛剤であるエテンザミド原薬をモデ ル薬物として採用し, Table 1 に示す配合比で懸濁液を調 製し，これを湿式粉砕した。粉砕回数ごとにおける光学 顕微鏡写真と平均粒子径測定結果を Fig. 4 に示す。

光学顕微鏡写真から, 柱状のエテンザミドは粉砕回数 を多くすることで, 微粒化する様子を確認した。一方, 平均粒子径測定值は粉砕回数に依存しなかった。原料の $100 \mathrm{~mL}$ の水に対する溶解度は, 日本薬局方より, 薬物工 テンザミドは水にほとんど溶けない $(0.1 \mathrm{~g}$ 未満）（不溶 性原料), 乳糖は水に溶けやすい $(16 \mathrm{~g})$ (水溶性原料), コーンスターチは水にほとんど溶けない $(0.1 \mathrm{~g}$ 未満)（不 溶性原料）に分類される。さらにコーンスターチは水を 取り込む性質を有する。

すなわち粉砕回数 10 pass 条件では懸濁液中に乳糖は 溶解しているが, 固形物として, 微粒化されたエテンザ ミドと初期形状を留めたコーンスターチが混在している ことになる。そこで, 光学顕微鏡の写真を拡大して確認 したところ, 粉确回数 10 pass 条件においてもコーンス ターチは原料と同じ形状と大きさを維持していることが, 確認された。このことが, 平均粒子径が粉碳処理によっ ても変化しなかった要因と考えられる。粉砕装置のイン ターアクションチャンバー（IXC）内の微小経路は $85 \mu \mathrm{m}$ であり，コーンスターチ原料の大きさは約 $20 \mu \mathrm{m}$ であ る。通常はこの微小経路を高圧下で通過するため剪断力 により粉砕されるが, コーンスターチは塑性変形するこ とで通過したものと思われる。

次にこれらの湿式粉砕処理後の懸濁液を用い, 顆粒化 を行った。顆粒の SEM 写真を Fig. 5 に示す。

SEM 写真から粉挽回数による顆粒形状の明確な変化は 認められなかった。

Fig. 6 には, 粉砕回数と円形度の関係を示す。粉砕回 数の増加に伴い顆粒の円形度は球形に近づく傾向を示し たが, 同一サンプル中の 10 個の顆粒間のばらつきが大き いため有意な差は認められなかった。

次に連続式顆粒化装置で得られた顆粒を, $180 \mu \mathrm{m}$ 以 上, $180 \sim 106 \mu \mathrm{m}, 106 \mu \mathrm{m}$ 以下の 3 分画にふるい分けし, 各粒度別の薬物含量を定量した。その結果を Fig. 7 に示 す。また, 粉研回数ごとに薬物含量の最大值と最小值（含 optical microscope images, magnification 200x

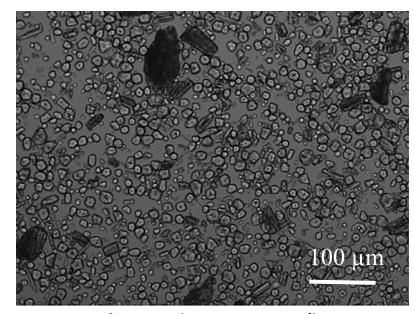

0 pass (unprocessed)

$\mathrm{D}_{50}: 16.1 \mu \mathrm{m}$

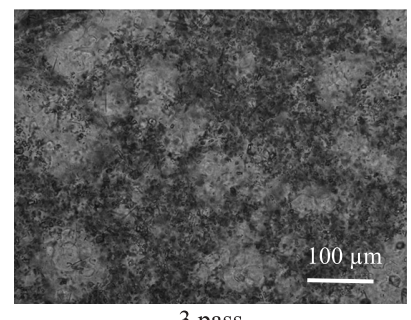

3 pass
$\mathrm{D}_{50}: 20.3 \mu \mathrm{m}$
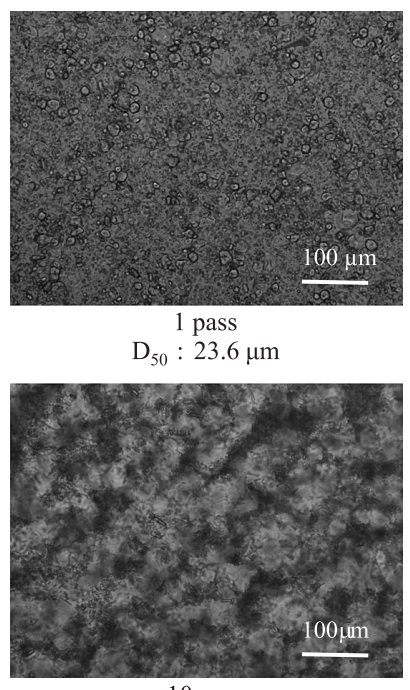
$\mathrm{D}_{50}: 17.0 \mu \mathrm{m}$
Fig. 4 Shapes and mean particle sizes of suspensions

SEM images, magnification 200x

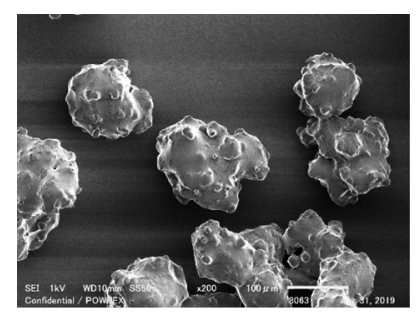

0 pass (unprocessed)

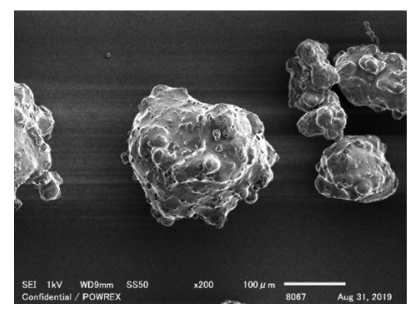

3 pass

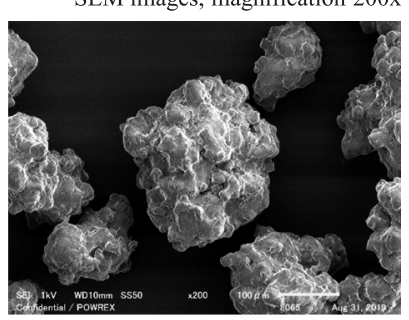

1 pass

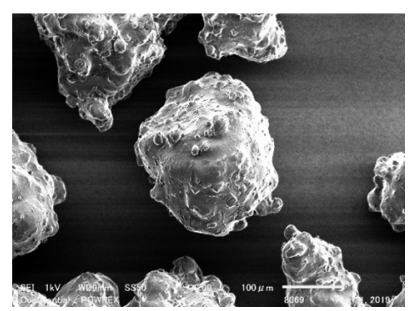

10 pass
Fig. 5 SEM observation of granules shape

量の最大と最小のばらつき）について Fig. 8 に示す。

Fig. 7 の結果より, 顆粒の粒子径が大きいほど薬物含 量は多い結果となった。特に 0 pass 条件では, 懸濁液中 の大きな薬物結晶が, 大きな顆粒に含まれやすくなるた 


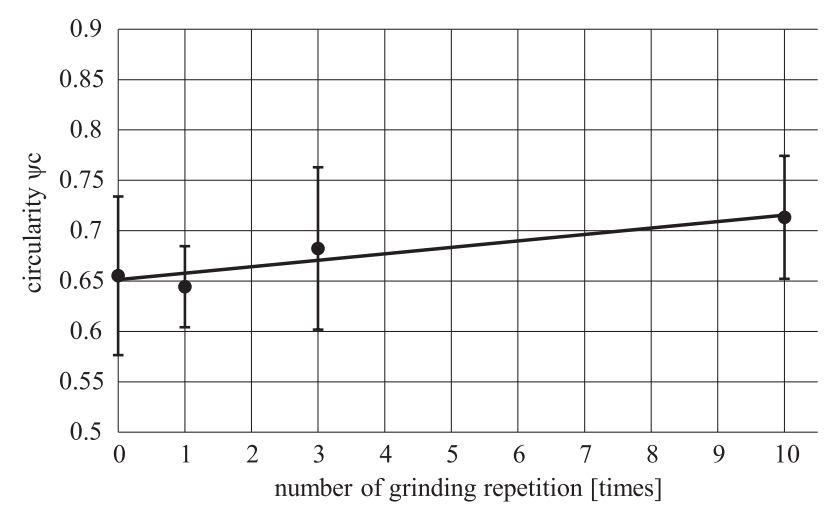

Fig. 6 Correlation between circularity and frequency of grinding repetition
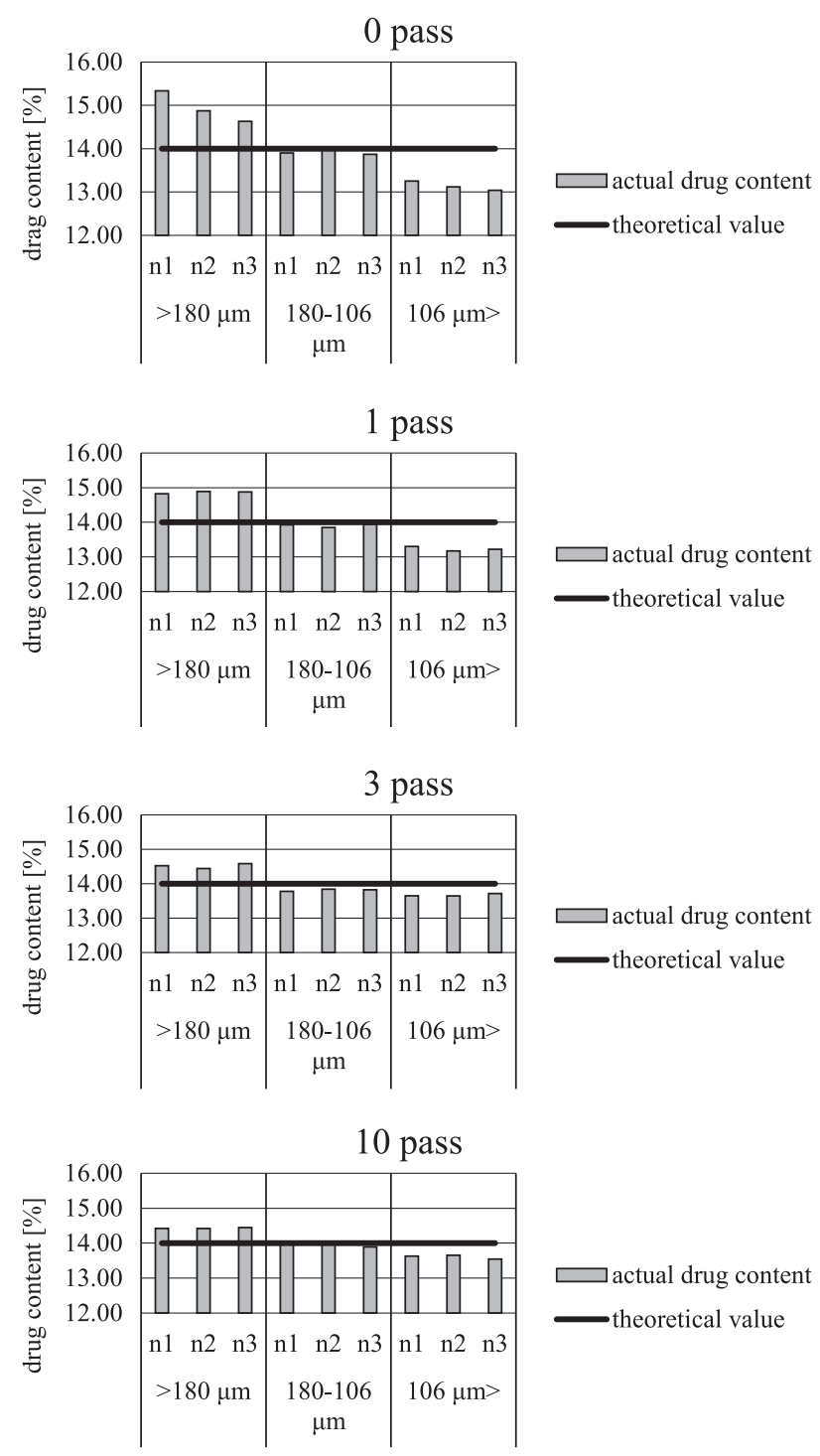

Fig. 7 Comparison of drug content in each particle fraction

め, $180 \mu \mathrm{m}$ 以上分画で高い含量を示した。粉砕の進行と 伴に薬物が小径化し，スプレーミスト中の薬物量が均一 となることで, 顆粒薬物含量が均一になると考えられた。

また, Fig. 8 の結果より, 粉砕回数を多くすることで 薬物含量のばらつきも小さくなる傾向を示した。

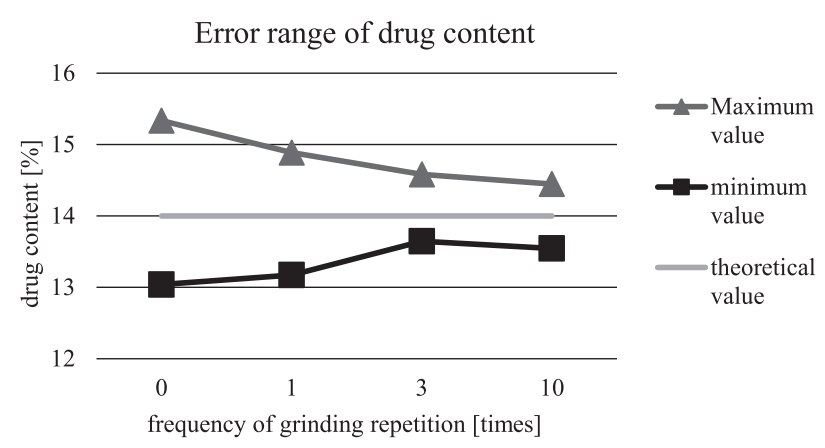

Fig. 8 Correlation of frequency of grinding repetition and dispersion of drug content

optical microscope images, magnification 200x

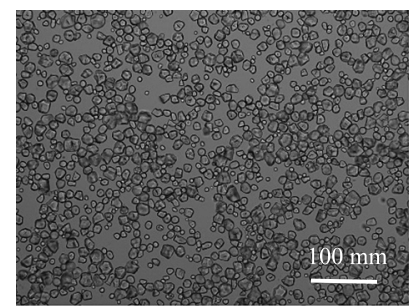

0 pass (unprocessed) $\mathrm{D}_{50}: 15.3 \mu \mathrm{m}$

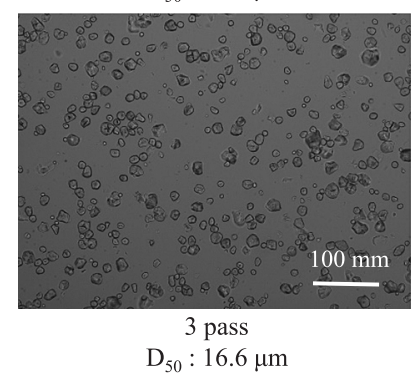

Fig. 9 shapes and mean particle size of suspensions

\subsection{1 コーンスターチの微細化検討}

4.1 の実験において, コーンスターチが粉砕されていな いことが明らかとなった。そこで, 追加実験としてコー ンスターチのみを水に懸濁し粉砕が可能かを検証した。 粉砕回数ごとにおける光学顕微鏡写真と平均粒子径測 定結果を Fig. 9 に示す。

本結果は 4.1 と同様, 粉砕回数と平均粒子径に相関が ない結果であった。また光学顕微鏡写真から粒子数が減 少している様子が伺える。これはコーンスターチが $70^{\circ} \mathrm{C}$ 以上に加熱することで糊化する特徵 [1]を持つことに起因 すると考え, 実験後にコーンスターチの粉砕事例につい て調査した。湿式のビーズミルを使用した粉砕事例では 加熱せず，粉砕しても55\%が糊化したとの報告があり [2], この事象により粉砕回数に応じて粒子数が減少した と考える。また糊化を防ぐ手段として $\mathrm{pH}$ を 12.0 以上と することで, 糊化が起こりにくく粉砕が可能となるとの 報告がある[3]。このような原料特性を考慮した粉砕条件 の設定が必要であると考えられる。

\section{2 粉砕による球形化確認}

4.1 の結果より, コーンスターチの粉砕が困難であるこ 
Table 2 Materials for experiment

\begin{tabular}{lccc}
\hline Materials & manufacturer & $\begin{array}{c}\text { Mixing ratio } \\
\text { of the water } \\
\text { solution (wt.\%) }\end{array}$ & $\begin{array}{c}\text { Mixing ratio } \\
\text { of granules (wt. } \%)\end{array}$ \\
\hline $\begin{array}{l}\text { Ethenzamide } \\
\text { Hydroxypropyl Cellulose }\end{array}$ & IWAKI SEIYAKU CO., LTD. & $15.0 \%$ & $83.3 \%$ \\
purified water & NIPPON SODA CO., LTD. & $3.0 \%$ & $16.7 \%$ \\
\hline
\end{tabular}

optical microscope images, magnification 200x

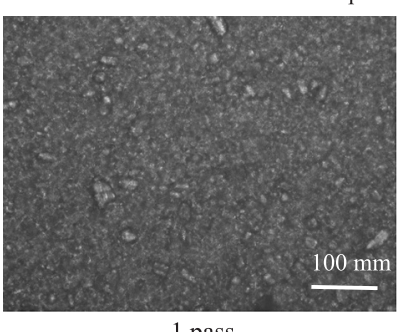

1 pass $\mathrm{D}_{50}: 19.5 \mu \mathrm{m}$

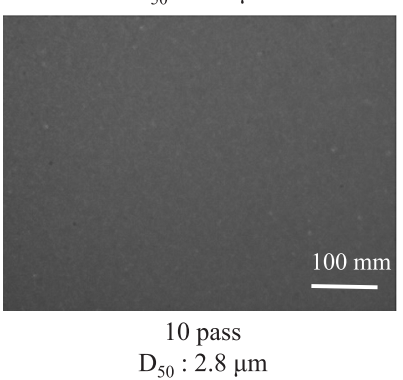

Fig. 10 Shapes and mean particle sizes of suspensions

とから，懸濁物質の粒子径と連続式顆粒化装置で得られ る顆粒の円形度の相関を明らかにするため, コーンスター チを除いた Table 2 に示す処方にて同様の検討を行った。 本処方はエテンザミドが $80 \%$ 以上を占め, 薬物粒子径の 影響を受けやすい処方になっている。

本処方の懸濁液を粉砕し, その評価として光学顕微鏡 による写真と平均粒子径を測定した結果を Fig. 10 に示 す。

結果として平均粒子径の測定結果と光学顕微鏡写真の 様子が一致しており，粉砕回数を多くすることによって 懸濁物質の粒子が小さくなることを確認した。

次に湿式粉砕後の懸濁液を用い，顆粒化を行った。 SEM 写真を Fig. 11 に示す。なお, 本実験では未粉砕の 懸濁液については顆粒化前にスプレーノズル先端の液流 路が懸濁物で閉塞する現象が発生し，顆粒化することが できなかった。

得られた顆粒について粉砕回数が少ない条件では粒子 表面の突起が多く，不定形な形状であるのに対し，粉砕 回数を多くすることによって突起が減少し，形状も球形 に近づく様子を確認した。円形度の結果を Fig. 12 に示 す。䀣濁物を 10 pass 粉砕し, 平均粒子径を $2.8 \mu \mathrm{m}$ とす ることで，0.85という高い円形度を示した。また全体的

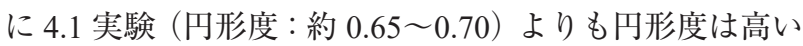
值となった。
SEM images, magnification 200x

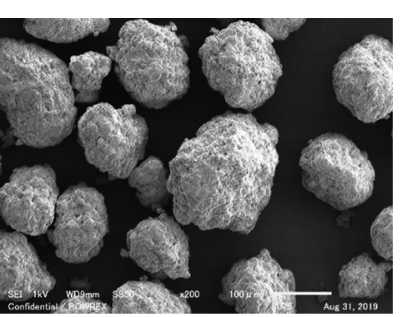

1 pass

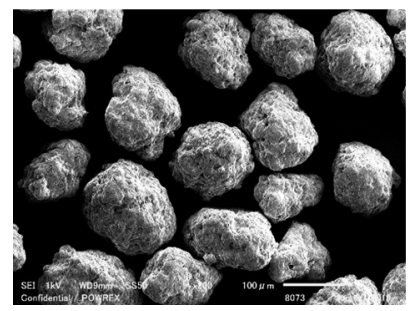

10 pass

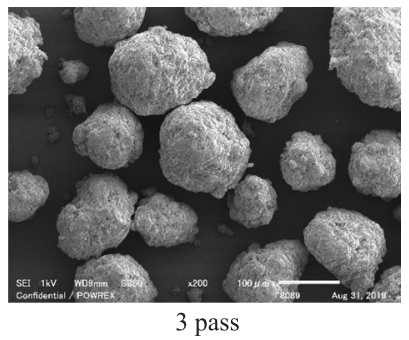

Fig. 11 SEM observation of granules shape

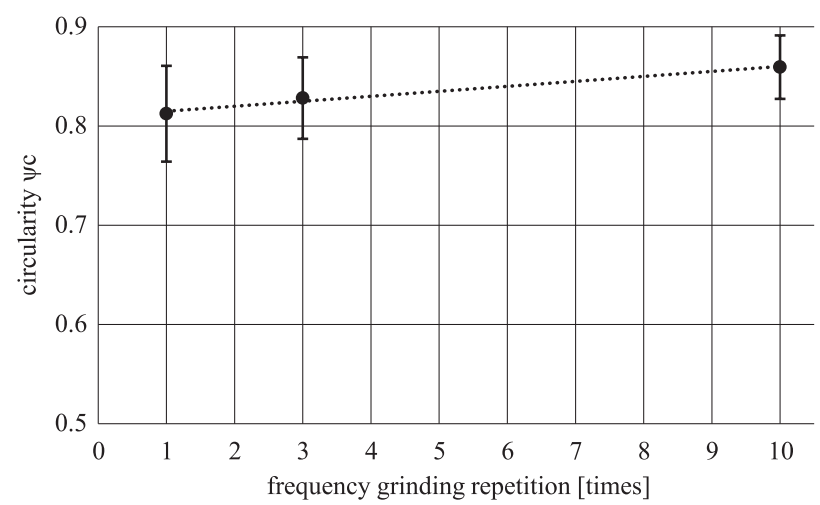

Fig. 12 Correlation between circularity and frequency of grinding repetition

\section{3 水溶性添加剂が顆粒の球形度におよぼす影響}

4.1 では 10 pass 条件でも粉砕前と同じ約 $20 \mu \mathrm{m}$ のコー ンスターチが存在したため, 円形度は 0.7 程度と低くなっ た。 4.2 では粉砕されにくいコーンスターチを取り除き, 懸濁物質である薬物の平均粒子径を小さくすることで, 球形度が向上することを示した。ここでは, 不溶性原料 の粉砕処理を実施せず, 水溶性原料を多めに添加するこ とで，顆粒表面の粗度を補填できないかを検討した。

本実験では不溶性原料としてエテンザミド，水溶性原 料としてマンニットを用いた。なおマンニットの溶解度 は水 $100 \mathrm{~mL}$ に対し $20 \mathrm{~g}$ である。 
Table 3 Materials for experiment

\begin{tabular}{llcc}
\hline Materials & manufacturer & $\begin{array}{c}\text { Mixing ratio } \\
\text { of the water } \\
\text { solution (wt.\%) }\end{array}$ & $\begin{array}{c}\text { Mixing ratio } \\
\text { of granules (wt.\%) }\end{array}$ \\
\hline Ethenzamide & IWAKI SEIYAKU CO., LTD. & $2.8 \%$ & $14.0 \%$ \\
Mannitol & Mitsubishi Corporation Life Sciences Limited & $16.0 \%$ & $80.0 \%$ \\
Hydroxypropyl Cellulose & NIPPON SODA CO., LTD. & $1.2 \%$ & $6.0 \%$ \\
purified water & - & $80.0 \%$ & - \\
\hline
\end{tabular}

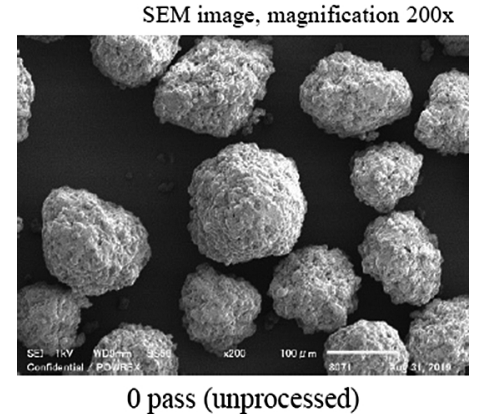

Fig. 13 SEM observation of granules shape

\section{処方を Table 3 に示す。}

上記処方で懸濁液を調製し，粉碳処理は実施せず顆粒 化を実施した。懸濁液中のエテンザミド平均粒子径は $51.4 \mu \mathrm{m}$ であった。得られた顆粒の SEM 写真を Fig. 13 に示す。

4.2 の 0 pass 条件の懸濁液をスプレー噴霧した際にはス プレーノズル先端の液流路が懸濁物で閉塞する現象が発 生したが，本検討では懸濁物質濃度が低いため，ノズル が閉塞することなく顆粒化できた。なお，4.2 で用いた懸 濁液中の不溶性原料は $15 \%$ であったのに対し，本検討で は $2.8 \%$ でる。

本結果から懸濁物の粒子径が大きくても処方に水溶性 原料を多く含むことで顆粒形状は球形に近づき，円形度 は 0.83 を示した。また, 4.2 の 10 pass 条件で粉砕後に顆 粒化した円形度が 0.85 であり, 粉砕処理を実施せずと も，ほぼ同等の球形顆粒を得ることができた。水溶性原
料の割合も重要な因子であり, 本結果から顆粒配合比と して $80 \%$ の水溶性原料があれば球形化することを確認し た。

\section{5. 結言}

顆粒の粒子形状は懸濁液中の粒子径に依存しているこ とを確認した。顆粒の粒子径の約 $1 / 20$ の大きさまで懸濁 液中の懸濁物質の粒子径を小さくすることで球形度が高 くなることを確認した。また，懸濁液中に $80 \%$ ほどの水 溶性原料を加えることで, 懸濁物同士が結合する隙間を 水溶性原料が埋め, 薬物結晶を粉砕することなく顆粒を 球形化できることを確認した。

粒度別含量については, 成分のばらつきを少なくする ためには不溶性原料を粉砕し, 微細化することが有効で あることを確認した。

以上の結果より, 顆粒の形状として球形顆粒を得る目 的のみであれば, 不溶性原料に水溶性原料を加えること で対応可能であることが示唆された。粒度別含量を均一 にする目的とするのであれば，不溶性原料粒子径を小さ くすることが重要であることを確認した。

今回の実験は短時間で顆粒を製し, 粒度別含量は粒子 径の大きさにより変動する様子が確認できた。しかし連 続式顆粒化装置は本来分級しながら所望の粒子径のみを 連続的に得る装置であるため, 不溶性原料粒子径が一定 の大きさで存在すると, 顆粒化工程を長時間運転した際 には，時間ごとに成分量が変動する可能性があり，プロ セスとしては粉砕操作が必要不可欠であると考える。

\section{References}

[1] M. Hirashima, R. Takahashi, M. Hiroe, K. Nishinari, Effects of micro-crystaline cellulose on gelatinization and retrogradation for cornstarch gels, The Japan Society of Cookery Science 43 (2010) 168-175.
[2] C. Chen, Y. Shen, A. Yeh, Physico-chemical characteristics of media-milled corn starch, J. Agric. Food Chem. 58 (2010) 9083-9091.

[3] M. Hirashima, Texture control of alkalized starch pastes or starch gels, Grants-in-Aid for Scientific Research, 24500942 